\title{
Critical Values in Laboratory Tests of Iranian Patients Referring to Laboratories: A Cross-sectional Study in Kerman
}

\author{
Elham Jafari, MD, APCP1*; Farideh Zarnegar, MD²; Mahtab Kalantari, BSc ${ }^{1}$; Shahriar Dabiri, MD, APCP1; Ahmad Naghibzadeh- \\ Tahami, $\mathrm{PhD}^{3}$ \\ ${ }^{1}$ Pathology and Stem Cells Research Center, Kerman University of Medical Sciences, Kerman, Iran \\ ${ }^{2}$ Clinical Research Development Unit, Afzalipour Hospital, Kerman University of Medical Sciences, Kerman, Iran \\ ${ }^{3}$ Neuroscience Research Center, Institute of Neuropharmacology, Kerman University of Medical Sciences, Kerman, Iran
}

\begin{abstract}
Background: Laboratory services play an important role in optimizing patient care today, and the importance of clinical laboratories is now widely accepted in medical practice. A critical value, originally described by Lundberg more than 30 years ago, refers to an abnormal test result that can lead to a serious life threat if not reported in a timely manner. In this study, we tried to determine the importance of critical values that can lead to a serious life threat with regard to their prevalence and frequency in laboratory tests of Iranian patients.

Methods: In this cross-sectional study, the frequency of critical values in laboratory tests were determined and compared according to the type of laboratory parameter, age, sex, the inpatient/outpatient status, the related clinical ward, recurrence of critical values in the patient's test results, and the sampling working shift in Shahid Bahonar hospital in Kerman, Iran, in 2017 and 2018.

Results: Among the tests, $0.2 \%$ had critical results. There was a significant relationship between the frequency of critical results with the patients' age $(P=0.002)$ and sex $(P=0.001)$ as well as with sampling working shift $(P=0.030)$ and admission ward $(P=$ 0.001). Among the tests with critical values, the urea test was the most common with $32.2 \%$ critical value incidence.

Conclusion: To maintain patient safety, proper recording of the results in laboratory tests and prompt reporting of critical values to the health care staff before repeating the test should be emphasized.

Keywords: Clinical laboratory services, Iran, Laboratory critical values

Cite this article as: Jafari E, Zarnegar F, Kalantari M, Dabiri S, Naghibzadeh-Tahami A. Critical values in laboratory tests of iranian patients referring to laboratories: a cross-sectional study in kerman. Arch Iran Med. 2021;24(6):473-477. doi: 10.34172/ aim.2021.68
\end{abstract}

Received: October 28, 2020, Accepted: January 13, 2021, ePublished: June 1, 2021

\section{Introduction}

Nowadays, laboratory assays are an important part of the health care system, with a well-established role in clinical decision-making and prognosis. ${ }^{1-3}$ Critical values are very life-threatening high or low measurements in laboratory tests and should be reported promptly to the health care providers in order to develop better diagnostic and prognostic approaches and results by helping the personnel adopt better courses of action in patient treatment. ${ }^{4-8}$

Labs should inform patients and physicians of critical values so as to facilitate decision making as emphasized by the Joint Commission ${ }^{5}$ and College of American Pathologists. ${ }^{910}$ The methods used for determination of critical values are not the same across the countries and ethnic groups; these measurements should be determined separately in various regions, ${ }^{5,11}$ and periodical updates should be developed to improve the quality of the results. ${ }^{2}$ Also homogenizing the results may be done to facilitate the comparison of results worldwide. ${ }^{6}$ The race, age, and sex differences should be respected during such processes. ${ }^{4}$

Preparation of lists for critical values should be both concise and definite without either over- or under- reporting in the lists as each one can be detrimental to patients' health. ${ }^{2}$ The Joint Commission on Accreditation of Healthcare Organizations (JCAHO) has focused on critical values to improve patient safety, ${ }^{12-14}$ and the Clinical Laboratory Improvement Amendments (CLIA) has determined the reporting of such values as an important global goal..$^{15}$ This should be done in a time schedule according to that suggested by the Joint Commission. ${ }^{16}$

The report of critical values by lab staff or alarm signals sent by programmed devices is the main initial step to take action in response to them, which should be done after repeating the tests to confirm the results. ${ }^{2}$ The reporting process may be done by phone calls or computerized alarms directed at either the patient or the physician. ${ }^{2}$ Lab/hospital-based information systems are more accurate methods to decrease chances of error ${ }^{4}$ and also to save time. ${ }^{2}$ The mean time interval to report critical values is approximately 6 hours and 14 minutes for inpatients and outpatients, respectively. ${ }^{8}$ The rational and appropriate time interval is between 15 and 30 minutes $^{8}$ and standardization of critical values are important steps in relation to this matter. ${ }^{2}$ 
There is little information on repeating critical values or later critical values for the same analyte(s) in the same patient. ${ }^{17,18}$ There is no clinical congruence between those with a higher number of critical values or repeating critical values and those who have shown them only once. On average, the critical values are repeated for each patient every eight hours. ${ }^{18}$ However, avoiding test repeats can lead to faster approaches and lower costs. ${ }^{1}$ Regarding the importance of reporting critical values for the improvement of health care provision and better outcomes in patients, ${ }^{18-25}$ in this study, the frequency of tests reporting critical values, the type of test and critical value, the values themselves, and the recurrence of critical values were assessed.

\section{Materials and Methods}

In this cross-sectional descriptive-comparative study, a total of 2146 consecutive critical values based on type of laboratory parameter, age, sex, inpatient/outpatient status, associated clinical ward, repetition of patient's critical values, and sampling working shift were collected and compared in Shahid-Bahonar hospital in Kerman, Iran, in 2017 and 2018.

The inclusion criteria were inpatient/outpatient admission to the hospital and undergoing laboratory assessment. The laboratory tests consisted of fasting blood sugar (FBS), urea, creatinine, calcium, sodium, potassium, phosphorus, platelet, hemoglobin, and microbiology assays. The leukocyte count was not assessed because of the presence of two wards of adult hematology in the hospital with repeated low leukocyte count in patients. Data were collected from patient healthcare documents and the hospital health information system (HIS). The critical values were examined according to the DLMP Critical Results/Critical Values List and pathology reference textbooks.

Data analysis for the 2146 patients was done with SPSS version 22.0 The tests used for comparisons in this study were ANOVA and independent samples $t$ test. $P$ values less than 0.05 were considered statistically significant.

\section{Results}

Biochemistry assays and microbial culture tests were the main samples with critical values (Table 1). In total, 2032 patients $(94.7 \%)$ were older than 14 years $(P=0.002)$. Also, 1284 cases $(60 \%)$ were male, yielding an $\mathrm{M} / \mathrm{F}$ ratio of $3: 2(P=0.001)$.

The critical values were detected in $58.5 \%, 29.0 \%$, and $12.5 \%$ of morning, evening, and night work shifts, respectively $(P=0.030)$. As shown in Figure 1 , the intensive care unit (ICU) (24\%) and emergency ward (13.2\%) had the highest number of critical values $(P=$ 0.001). In total, $96.7 \%$ of cases with critical values were inpatients. As seen in Table 2, the microbiological tests had the highest occurrence of critical values (6.6\%), and among the biochemical tests, the urea test had the highest number of critical values (31.5\%).
Table 1. Critical Values by Year and Admission Status

\begin{tabular}{lcccc}
\hline Test Group & Status & Year & Frequency & Percent \\
\hline Biochemistry & Inpatient & 2017 & 830 & 38.6 \\
\hline Biochemistry & Inpatient & 2018 & 599 & 28.0 \\
Biochemistry & Outpatient & 2017 & 14 & 0.65 \\
\hline Biochemistry & Outpatient & 2018 & 38 & 1.8 \\
\hline Hematology & Inpatient & 2017 & 33 & 1.52 \\
\hline Hematology & Inpatient & 2018 & 40 & 1.86 \\
\hline Hematology & Outpatient & 2017 & 11 & 0.5 \\
\hline Hematology & Outpatient & 2018 & 7 & 0.32 \\
Microbial Culture & Inpatient & 2017 & 354 & 16.5 \\
\hline Microbial Culture & Inpatient & 2018 & 220 & 10.25 \\
\hline Total & - & - & 2146 & 100 \\
\hline
\end{tabular}

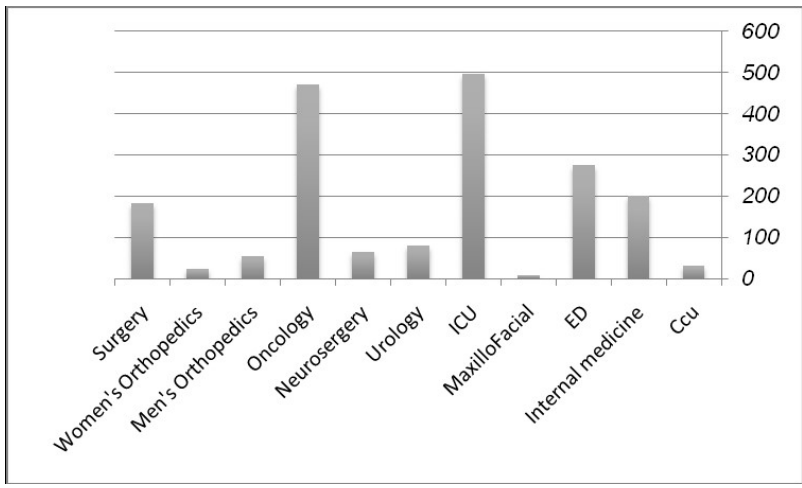

Figure 1. Critical Values by Admission Wards

Table 2. Critical Values by Type of Test

\begin{tabular}{ccccc}
\hline Tests & $\begin{array}{c}\text { Critical } \\
\text { Test Results }\end{array}$ & $\begin{array}{c}\text { Percentage of } \\
\text { All Critical Test } \\
\text { Results }\end{array}$ & $\begin{array}{c}\text { Total Test } \\
\text { Volume }\end{array}$ & $\begin{array}{c}\text { Percentage of } \\
\text { Test Volume } \\
\text { with a Critical } \\
\text { Test }\end{array}$ \\
\hline FBS & 279 & 13 & 64134 & 0.4 \\
\hline Urea & 676 & 31.5 & 105469 & 0.6 \\
\hline Cr & 274 & 12.8 & 106626 & 0.2 \\
\hline Ca & 13 & 0.6 & 32969 & 0.03 \\
\hline Na & 94 & 4.4 & 95024 & 0.09 \\
\hline K & 130 & 6.0 & 99169 & 0.13 \\
\hline Ph & 15 & 0.7 & 27469 & 0.05 \\
\hline Plt & 67 & 3.1 & 174080 & 0.03 \\
\hline Hb & 24 & 1.1 & 173973 & 0.013 \\
\hline Microbiology & 574 & 26.8 & 8689 & 6.6 \\
\hline Total & 2146 & 100 & 887602 & 0.2 \\
\hline
\end{tabular}

FBS, fasting blood sugar; $\mathrm{Cr}$, creatinine; $\mathrm{Ca}$, calcium; $\mathrm{Na}$, Sodium; $\mathrm{K}$, potassium; $\mathrm{Ph}$, phosphorus; $\mathrm{Hb}$, hemoglobin; Plt, platelets.

The results of various tests in comparison with the reference list are shown in Table 3.

Figure 2 shows the number of repeats of each test along with the critical value. The majority of recurrences of critical values were reported in the initial admission ward. Also, according to Figure 3, the majority of repeats were in patients admitted to the ICU (42.2\%). 
Table 3. Mean and Standard Deviation for Tests with Critical Values

\begin{tabular}{|c|c|c|c|c|c|c|}
\hline Test & $\begin{array}{l}\text { High/ } \\
\text { Low }\end{array}$ & $\begin{array}{c}\text { Critical } \\
\text { Value }\end{array}$ & Units & $\begin{array}{c}\text { Total } \\
\text { number }\end{array}$ & Mean & SD \\
\hline $\mathrm{Hb}$ & $\mathrm{H}$ & $20 \geq$ & $\mathrm{g} / \mathrm{dL}$ & 2 & 20.1 & 0.1 \\
\hline $\mathrm{Hb}$ & $\mathrm{L}$ & $6 \leq$ & $\mathrm{g} / \mathrm{dL}$ & 22 & 4.0 & 1.21 \\
\hline Plt & $\mathrm{H}$ & $1000 \geq$ & $\times 10^{9} / /$ & 6 & 2554.2 & 1727.21 \\
\hline Plt & $\mathrm{L}$ & $40 \leq$ & $\times 10^{9} / /$ & 61 & 16.5 & 10.36 \\
\hline $\mathrm{Ca}$ & $\mathrm{H}$ & $13 \geq$ & $\mathrm{mg} / \mathrm{dL}$ & 7 & 13.5 & 0.7 \\
\hline $\mathrm{Ca}$ & $\mathrm{L}$ & $6 \leq$ & $\mathrm{mg} / \mathrm{dL}$ & 6 & 4.1 & 2.1 \\
\hline $\mathrm{Cr}$ & $\mathrm{H}$ & $5 \geq$ & $\mathrm{mg} / \mathrm{dL}$ & 274 & 7.8 & 1.8 \\
\hline FBS & $\mathrm{H}$ & $400 \geq$ & $\mathrm{mg} / \mathrm{dL}$ & 231 & 504.1 & 132.2 \\
\hline FBS & $\mathrm{L}$ & $400 \leq$ & $\mathrm{mg} / \mathrm{dL}$ & 48 & 30.2 & 9.2 \\
\hline Urea & $\mathrm{H}$ & $100 \geq$ & $\mathrm{mg} / \mathrm{dL}$ & 676 & 141.5 & 35.5 \\
\hline $\mathrm{Ph}$ & $\mathrm{H}$ & $8.9 \geq$ & $\mathrm{mg} / \mathrm{dL}$ & 11 & 10.0 & 1.7 \\
\hline $\mathrm{Ph}$ & $\mathrm{L}$ & $1 \leq$ & $\mathrm{mg} / \mathrm{dL}$ & 4 & 0.9 & 0.1 \\
\hline K & $\mathrm{H}$ & $6.2 \geq$ & $\mathrm{mmol} / \mathrm{L}$ & 69 & 7.0 & 0.65 \\
\hline $\mathrm{K}$ & $\mathrm{L}$ & $2.8 \leq$ & $\mathrm{mmol} / \mathrm{L}$ & 61 & 2.3 & 0.36 \\
\hline $\mathrm{Na}$ & $\mathrm{H}$ & $160 \geq$ & $\mathrm{mmol} / \mathrm{L}$ & 46 & 167.0 & 7.4 \\
\hline $\mathrm{Na}$ & $\mathrm{L}$ & $120 \leq$ & $\mathrm{mmol} / \mathrm{L}$ & 48 & 118.0 & 1 \\
\hline
\end{tabular}

FBS, fasting blood sugar; $\mathrm{Cr}$, creatinine; $\mathrm{Ca}$, calcium; $\mathrm{Na}$, Sodium; $\mathrm{K}$, potassium; $\mathrm{Ph}$, phosphorus; Plt, platelets; $\mathrm{Hb}$, hemoglobin; $\mathrm{H}$, high; L, low; SD, standard deviation.

\section{Discussion}

In this study, there was a total of 887602 tests, among which 2146 cases $(0.2 \%)$ had critical values consisting of 1481, 91, and 574 tests in biochemistry, hematology, and microbiology assays. The rate is raised to 0.35 if repeat tests are taken into account. Age above 14 years $(P=0.002)$, male sex $(P=0.001)$, morning work shift $(P=0.030)$, and ICU $(23.2 \%)$ and emergency ward (12.8\%) admission $(P$ $=0.001)$ were factors affecting critical values. The higher incidence of critical values in morning shift is related to more test requests in this shift and also the limitation of the tests to the emergency assays in other work shifts. Similarly, Dighe et $\mathrm{al}^{12}$ reported the ICU and emergency ward as wards with the highest number of critical values ( $45 \%$ and $44 \%$, respectively), but their reported rates were not similar to our results. Also, they assessed a total of 14 million lab tests with a critical value rate of $25 \%$. Similar to our study, the rates were higher in inpatients compared to outpatients.

In our study, microbial cultures had the highest rates of critical values among microbiology tests, with a rate of $6.6 \%$, and among the biochemical tests, $31.5 \%$ of urea tests had critical values. Also, with a rate of $32.2 \%$, urea tests had the highest overall rates in patients. Arbiol-Roca et $\mathrm{al}^{4}$ reported that the rate of critical values was $0.4 \%$ in a Spanish training hospital. In their study, arterial blood gas was the most common test with positive critical values; this parameter was not assessed in our study due to some limitations.

In our study, the tests results were subdivided to high

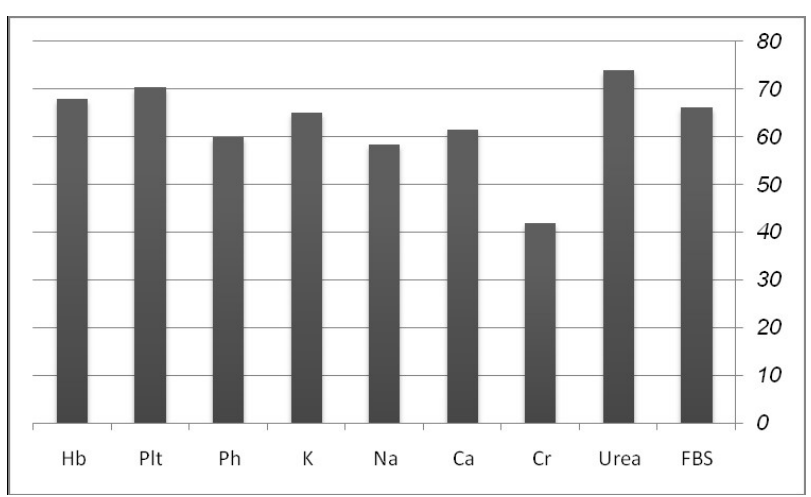

Figure 2. Percentage of Critical Values Repeated for Each Test.

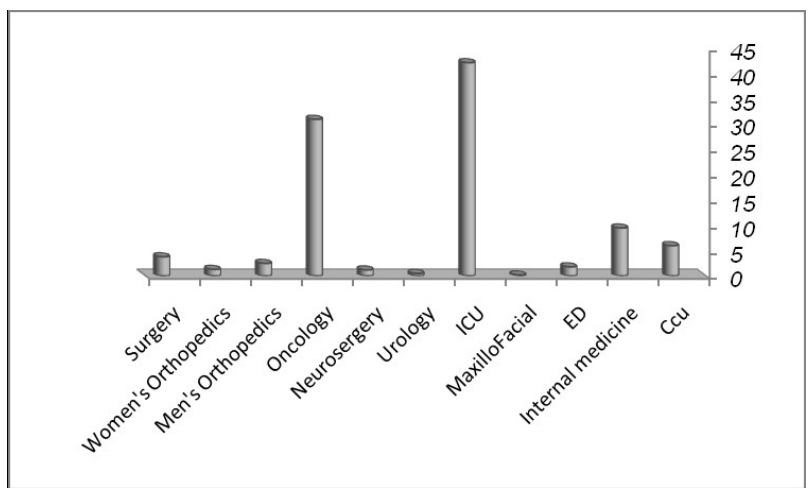

Figure 3. Percentage of Repeated Critical Values in Patients Admitted to Each Clinical Ward.

and low according to the reference list. Kuperman et $\mathrm{al}^{19}$ also divided the results into high and low groups. In their study, the $\mathrm{PO}_{2}$ test had the highest rate of critical values, and the time interval between report and treatment was 150 minutes, which shows the malfunction of the health care providers despite prompt acknowledgement of critical values. Wagar et $\mathrm{al}^{5}$ compared the critical values according to age. In contrast with this study, they found no significant association with calcium, potassium, and hemoglobin levels. In addition, in their study, sex had no relationship with critical values.

In our study calcium, consisting of six low and seven high measures and mainly detected in the ICU, oncology, and internal wards, had critical values in 13 cases $(0.03 \%)$. In a study by Howanitz et al, ${ }^{14}$ critical values for calcium were reported in $1.4 \%$ of the sample, and that was accompanied by a $25 \%$ mortality rate. They concluded that the current reference list is appropriate and it does not reed to be extended. In our study, the rate of critical values for sodium was $0.09 \%$ (94 cases), consisting of 48 and 46 cases with low and high serum sodium levels, respectively. The majority of cases were ICU-admitted. Another study by Howanitz et $\mathrm{al}^{13}$ showed a rate of $0.55 \%$ for critical values in sodium levels consisting of 447 and 166 cases with high and low sodium levels, respectively. However, that was a study on mortality rates. Our study was cross-sectional and, due to some restraints, outcome was not assessed in patients.

For potassium levels, $0.13 \%$ of the cases had critical values consisting of 61 and 69 cases with low and high 
levels, respectively, and the majority of them were admitted to the ICU. Zhou et $\mathrm{al}^{3}$ reported higher admission in internal wards such as hepatology and nephrology, which is not compatible with our results. Our results showed that clinical symptoms were related to critical values of serum potassium, but one important limitation was our inability to assess the symptoms. In our study, $65 \%$ of cases with critical values had repetition in such values. The possible explanations include; (1) presence of hemato-oncology and three ICU wards; (2) low socio-economic status in patients referring to this public hospital leading to delay in seeking care; (3) As this is a referral hospital for trauma cases, the majority of patients are admitted in critical conditions; (4) lack of recording or reporting of critical values by the lab to the health care staff leading to lack of treatment; (5) Transfer from the ward and change in the healthcare team. The presence of an alarm system in the hospital HIS can help us better prepare for cases with critical values leading to improvement of patient survival and prognosis.

A study by Yang et $\mathrm{al}^{18}$ showed the mean repeat rate of 2.1 times for critical values with a mean interval of eight hours. Patients with more repeats had worse prognoses. The mean time interval in our study was eighty minutes. One possible cause for this delay is the repeating of the suspected tests for confirmation. However, Baradaran Motie et $\mathrm{al}^{1}$ claimed there is no need for confirmation tests and that critical values should be informed at the earliest convenience. Sun et $\mathrm{a}^{23}$ reported the highest rate of critical values for platelet count, while the lowest rate pertained to leukocytes. In their study, it was established that the results of more than $95 \%$ of tests were repeated to confirm the critical values. The presence of clots in the initial sample may be the cause of this discrepancy. With cost-benefit analysis, it was found that the quality of equipment and devices can be a sufficient cause for earlier reporting of critical values to the health care staff. However the time needed for repetition of biochemical tests is different depending on the type of test. For instance, the time necessary is 17 and 42 minutes for blood sugar and calcium levels, respectively. ${ }^{25}$

Howanitz et $\mathrm{al}^{8}$ reported lower time for inpatient versus outpatient cases. Also, they reported the dependence of this factor on working shift, number of beds, and number of patients admitted in every ward. Piva et $\mathrm{al}^{6}$ reported critical values in $2.3 \%$, which led to alteration in the treatment course in $98 \%$ of surgical and $90 \%$ of non-surgical cases. They showed the importance of prompt notification of ward personnel of critical values in achieving better treatment outcomes.

The incomplete documentation of results during the two-year interval, despite instructions given to hospital staff, was an important finding of this study; as a result, all statistical data reported in this study were extracted from the hospital HIS. Therefore, considering the importance of recording data and timely notification of critical values to improve patient safety, critical values should be better managed and organized. The mean time interval for informing the critical values to the wards was eighty minutes, which is too long in comparison with other studies. This reveals the importance of using advanced auto-analyzers, using the same reference list for critical values, avoiding repeating tests, and using auto-alarm systems in the labs of training hospitals.

In conclusion, to maintain patient safety, proper recording of the results and prompt reporting of critical values of laboratory tests to the health care staff before repeating tests is of great importance. It seems that achievement of the desired conditions and infrastructures necessitates training the laboratory personnel and the medical staff, especially the physician and nurses, on how to deal with critical values, updating laboratory equipment, and installing alarm systems in the patient information system.

\section{Authors' Contribution}

EJ, FZ, MK, SHD and AN: Critical revision of the manuscript for important intellectual content. EJ and MK: Study concept and design. AN: Statistical analysis. FZ, EJ and SHD: Analysis and interpretation of data. EJ and FZ: Drafting of the manuscript.

\section{Conflict of Interest Disclosures}

The author declares no conflict of interest.

\section{Ethical Statement}

This study was approved by the Ethics Committee of Kerman University of medical sciences, Kerman, Iran, with the ethics code IR.KMU.AH.REC.1397.065.

\section{Acknowledgments}

We acknowledge the assistance of the staff of the Laboratory of Shahid Bahonar hospital affiliated with Kerman University of Medical Sciences.

\section{References}

1. Baradaran Motie P, Zare-Mirzaie A, Shayanfar N, Kadivar M. Does routine repeat testing of critical laboratory values improve their accuracy? Med J Islam Repub Iran. 2015;29:176.

2. Rocha BC, Alves JA, Pinto FP, Mendes ME, Sumita NM. The critical value concept in clinical laboratory. J Bras Patol Med Lab. 2016;52(1):17-20. doi: 10.5935/1676-2444.20160008.

3. Zhou F, Zhao B, Gu D. Evaluation of laboratory critical serum potassium values and their association with clinical symptoms in Chinese Han patients. J Int Med Res. 2015;43(6):851-61. doi: 10.1177/0300060515576011.

4. Arbiol-Roca A, Corral-Comesaña S, Cano-Corres R, Castro-Castro MJ, Dastis-Arias M, Dot-Bach D. Analysis of laboratory critical values at a referral Spanish tertiary university hospital. Biochem Med (Zagreb). 2019;29(1):010704. doi: 10.11613/bm.2019.010704.

5. Wagar EA, Friedberg RC, Souers R, Stankovic AK. Critical values comparison: a College of American Pathologists Q-Probes survey of 163 clinical laboratories. Arch Pathol Lab Med. 2007;131(12):1769-75. doi: 10.5858/2007-131-1769-cvcaco.

6. Piva E, Pelloso M, Penello L, Plebani M. Laboratory critical 
values: automated notification supports effective clinical decision making. Clin Biochem. 2014;47(13-14):1163-8. doi: 10.1016/j.clinbiochem.2014.05.056.

7. Piva E, Plebani M. From "panic" to "critical" values: which path toward harmonization? Clin Chem Lab Med. 2013;51(11):2069-71. doi: 10.1515/cclm-2013-0459.

8. HowanitzPJ, Steindel SJ, Heard NV.Laboratory criticalvalues policies and procedures: a College of American Pathologists Q-Probes study in 623 institutions. Arch Pathol Lab Med. 2002;126(6):663-9. doi: 10.5858/2002-126-0663-lcvpap.

9. Dighe AS, Jones JB, Parham S, Lewandrowski KB. Survey of critical value reporting and reduction of falsepositive critical value results. Arch Pathol Lab Med. 2008;132(10):1666-71. doi: 10.5858/2008-132-1666-socvra.

10. Tillman J, Barth JH. A survey of laboratory 'critical (alert) limits' in the UK. Ann Clin Biochem. 2003;40(Pt 2):181-4. doi: $10.1258 / 000456303763046148$.

11. Milevoj Kopčinović L, Trifunović J, Pavošević T, Nikolac N. Croatian survey on critical results reporting. Biochem Med (Zagreb). 2015;25(2):193-202. doi: 10.11613/bm.2015.019.

12. Dighe AS, Rao A, Coakley AB, Lewandrowski KB. Analysis of laboratory critical value reporting at a large academic medical center. Am J Clin Pathol. 2006;125(5):758-64. doi: 10.1309/r53x-vc2u-5ch6-tng8.

13. Howanitz JH, Howanitz PJ. Evaluation of serum and whole blood sodium critical values. Am J Clin Pathol. 2007;127(1):56-9. doi: 10.1309/q3y27qqlel19340a.

14. HowanitzJH, Howanitz PJ. Evaluation of total serum calcium critical values. Arch Pathol Lab Med. 2006;130(6):828-30. doi: 10.5858/2006-130-828-eotscc.

15. Valenstein PN, Wagar EA, Stankovic AK, Walsh MK, Schneider F. Notification of critical results: a College of American Pathologists Q-Probes study of 121 institutions. Arch Pathol Lab Med. 2008;132(12):1862-7. doi: 10.5858/132.12.1862.

16. Lippi G, Mattiuzzi C. Critical laboratory values communication: summary recommendations from available guidelines. Ann Transl Med. 2016;4(20):400. doi: 10.21037/atm.2016.09.36.

17. Campbell CA, Horvath AR. Harmonization of critical result management in laboratory medicine. Clin Chim Acta. 2014;432:135-47. doi: 10.1016/j.cca.2013.11.004.

18. Yang D, Zhou Y, Yang C. Analysis of laboratory repeat critical values at a large tertiary teaching hospital in China. PLoS One. 2013;8(3):e59518. doi: 10.1371/journal. pone.0059518.

19. Kuperman GJ, Boyle D, Jha A, Rittenberg E, Ma'Luf N, Tanasijevic MJ, et al. How promptly are inpatients treated for critical laboratory results? J Am Med Inform Assoc. 1998;5(1):112-9. doi: 10.1136/jamia.1998.0050112.

20. Kuperman GJ, Teich JM, Tanasijevic MJ, Ma’Luf N, Rittenberg E, Jha A, et al. Improving response to critical laboratory results with automation: results of a randomized controlled trial. J Am Med Inform Assoc. 1999;6(6):512-22. doi: 10.1136/jamia.1999.0060512.

21. Sirisali K, Manochiopinij S, Leelahakul P, Ruengrai V, Sattayakom A, Sirisali S. Critical value of the clinical laboratory test in Thailand. J Med Assoc Thai. 2010;93 Suppl 6:S22-7.

22. Genzen JR, Tormey CA. Pathology consultation on reporting of critical values. Am J Clin Pathol. 2011;135(4):505-13. doi: 10.1309/ajcp9izt7bmbcjrs.

23. Sun SP, Garcia J, Hayden JA. Repeating critical hematology and coagulation values wastes resources, lengthens turnaround time, and delays clinical action. Am J Clin Pathol. 2018;149(3):247-52. doi: 10.1093/ajcp/aqx156.

24. Fei Y, Zhao H, Wang W, He F, Zhong K, Yuan S, et al. National survey on current situation of critical value reporting in 973 laboratories in China. Biochem Med (Zagreb). 2017;27(3):030707. doi: 10.11613/bm.2017.030707.

25. Onyenekwu CP, Hudson CL, Zemlin AE, Erasmus RT. The impact of repeat-testing of common chemistry analytes at critical concentrations. Clin Chem Lab Med. 2014;52(12):1739-45. doi: 10.1515/cclm-2014-0331. 